\title{
PERSPECTIVA INTERNACIONAL NA ÁREA DA EDUCAÇÃO: INTRODUÇÃO TEMÁTICA
}

Rejane de Medeiros Cervi *

\section{Intıo d u çã o}

Há vinte anos atrás, a Sociedade Européia de Educação Comparada CESE - reunia seu quadro de especialistas em Valência, Espanha, para analisar as influências da investigação internacional sobre as políticas nacionais de educação. Naquele ocasião, exercitava-se a especulação sobre o trânsito de idéias nascidas além das fronteiras dos sistemas nacionais e que, com maior ou menor intensidade e permanência, acabavam por afetar as decisões e as práticas educacionais no âmbito particular dos Estados.

Dois anos mais tarde, em 1981, realizava-se, em Genebra, a X Conferência da CESE. Nessa oportunidade, discutia-se o lugar dos estudos comparados no quadro das teorias educacionais e sua contribuição na formulação das políticas escolares.

Os debates ressaltavam a dimensão internacional como um domínio que permitia aos estudos comparados ultrapassarem os tradicionais exercícios de mera distinção de estruturas e dinâmicas escolares.

Simultaneamente àqueles eventos, e, influenciados também por outras contribuições intrigantes, especialmente a de MARQUEZ (1972, 1981) FURTER $(1977,1978)$, LE THANH KHOI $(1980,1981)$, desenvolvíamos uma tentativa de sistematizar a matéria internacional dentro de uma perspectiva teórica própria.

A existência densa e difusa de fatos e discursos no campo da educação emergidos de fontes e óticas internacionais diversas já constituía, de per si,

* Doutora em Filosofia e Ciências da Educação pela Universidade de Barcelona, Prof. a Titular de Educação Comparada da UFPR, Prof. a Adjunta da Pontifícia Universidade Católica do Paraná 
uma boa justificativa para um empenho de ordenação. A partir desta constatação, reconhecia-se que as possibilidades de tratamento do que poderia constituir a perspectiva internacional na área da educação eram mais que amplas, diríamos, quem sabe, ilimitadas.

Até então, a reflexão sobre a educação tomada em uma escala internacional se traduzia em contribuições sugestivas e importantes, voltadas para uma prática imediata de intercâmbio e de assistência.

Na década de 70 e começo de 80, principalmente, alguns comparatistas dirigiram suas análises para conjuntos cada vez mais abrangentes de sistemas educacionais e para a fantástica trama cooperativa internacional que se havia instalado depois da Segunda Guerra Mundial, com a consolidação dos organismos internacionais que atuavam no campo da educação. Neste sentido, os inventários do movimento educacional do Bureau Internacional de Educação de Genebra e a Teoria das Correntes Educativas, de Pere Rosselló (1960) constituíram um avanço interpretativo da visão da escala internacional.

Os estudos relacionados às organizações educacionais internacionais davam relevo particular aos relatórios dos programas e projetos de assistência técnica e financeira e ao desdobramento analítico das deliberações e recomendações das grandes reuniões mundiais e regionais.

Paralelamente, outros estudos centravam-se sobre o significado e a polêmica que o papel, desempenhado pelas organizações no processo de cooperação cultural e educacional intergovernamental, sugeria. Servem de ilustração, aqui, as contribuições de SPEAKMAN (1968), FAURE (1972), ABRAHAM (1973), JUNOD (1973/4), JUNOY (1973-4), MAHEU (1974), THOMAS (1975), MITTER (1979), dentro de uma lista quase interminável de Autores, bem como a maior parte das publicações da UNESCO, OCDE, Comunidade Européia, entre outras.

A abordagem internacional incluía, também, ensaios sociológicos e políticos sobre o contexto transnacional das transações. Este conteúdo estava explicita ou implicitamente vinculado à problemática educacional. Neste conjunto se enquadram os estudos referentes à tese da dependência e da modernização, à crise mundial da educação, às teses desenvolvimentistas e prospectivas, dentre os quais possuem importância, inicial e distinta, os trabalhos apresentados por: HARBINSON e MYERS (1965), FRASE e BRICKMAN (1968), BRICKMAN (1968), DEUTSCH (1970), GEZI (1971), MARQUEZ (1972), FERNIG (1972), COOMBS (1973), JANE (1973), LATAPI (1973), REUCHLIN (1973), THOMAS (1975), ANWEILLER (1977), CARNOY (1977), PREISVERK (1978), MARKLUND (1979), ARNOVE (1980), DEBEAUVAIS (1980), EPSTEIN (1981).

No Brasil, à mesma época, a literatura nativa não oferecia incursões nos moldes dos estudos mencionados e, tampouco, respondia em qualquer 
grau à preocupação de teorização de um domínio como o que pretendíamos brindar em nossos estudos pós-graduados.

Pode-se afirmar, sem risco de cometer inverdade, que, no desabrigo curricular da Disciplina de Educação Comparada, mencionada como campo eletivo junto ao Curso de Pedagogia, as abordagens se restringiam a conteúdos onde prevaleciam as descrições sobre a educação estrangeira.

Nossa formação, patrocinada por organismos internacionais (fomos bolsista do Projeto Principal no.1 da UNESCO, no Curso de Especialistas em Educação para a América Latina, e da OIT, no Curso de Administração de Sistemas de Formação Profissional, em 1965 e 1972, respectivamente) e a experiência de pós-graduação junto à Universidade de Barcelona, de 19781981, combinada ao exercício docente da Disciplina de Educação Comparada por mais de trinta anos e a um academical attachment em Universidade canadense, além da vivência de grandes encontros mundiais nesta área, deram um sabor de fatalidade e irreversibilidade às nossas escolhas acadêmicas. Escolhas, aliás, que encontrariam todo tipo de dificuldade para se implementarem, dada a ausência de uma cultura internacionalista no cotidiano universitário brasileiro.

Se, por um lado, a Universidade nos permitia realizar amplas experiências externas, era na volta, na vivência interna, com a escassez de interlocutores no âmbito da rotina mais próxima e/ou de parceiros engajados nesta temática, que as nossas motivações eram maiormente desafiadas.

Delimitar os estudos da perspectiva internacional, configurar um domínio ainda não sistematizado, adaptando enfoques alternativos, constituiu-se em meta do nosso doutoramento e de todo o nosso empenho acadêmico, a partir de então.

\section{O poblema, pois, e a caminhada}

Desde os primórdios dos inventários diagnósticos e institucionais, o acervo da matéria sobre a educação, numa escala internacional, além de ter alcançado um volume respeitável, sempre foi gerado sob intenções e propósitos nem sempre transparentes.

Além disso, as ações a partir do campo institucional internacional instalaram e legitimaram uma ingerência virtual na programática educacional dos governos de países em desenvolvimento e subdesenvolvidos.

Tais condições impõem uma meditação mais demorada e cuidadosa sobre este fenômeno de internacionalização e justificam o apelo a categorias explicativas de especial potencial crítico.

Com base neste pré-julgamento, pois, têm origem os empenhos do nosso estudo sobre a perspectiva internacional na área da educação. Empe- 
nhos que se iniciam com uma dedicada seleção de fatos e conteúdos, sobre os quais e entre eles, tenta-se estabelecer relações.

Re-analisadas, essas relações facilitaram a classificação de grande parte dos enfoques aplicados ao âmbito educacional além das fronteiras de determinação das unidades políticas nacionais (CERVI, 1981).

O que representou, de início, uma tentativa preliminar de síntese de um processo de mundialização (CERVI, 1981, 1984, 1985, 1986, 1987, 1989) derivou, nos dias atuais, para uma preocupação analítica mais complexa dentro de um novo cenário, o da globalização da educação.

O presente Artigo constitui uma revisão de excertos de nossa Tese de Doutorado, defendida em 1981. Seu objetivo é introduzir o estudo do tema da perspectiva internacional na área da educação, margeando uma definição preliminar para este objeto e esboçando uma configuração problemática respectiva.

\section{Primeiras questões}

Não há um só caminho para se chegar à compreensão dos fenômenos e não haverá uma só verdade. No entanto, a longa viagem com destino precisa de roteiro e de pontos de ancoragem. No nosso caso, são estas primeiras questões as que, tornando explícitas nossas intenções dissertativas, criaram a possibilidade de alcançar o objetivo principal deste estudo.

A configuração analítica, bem o sabemos, contém a metade do caminho da resposta para a qual pendemos. Assim, entre muitas questões que poderiam ser introduzidas, elaboramos as que melhor pareceram sintetizar a fronteira problemática do tema a estudar: educação?

- O que se pode entender por perspectiva internacional na área da

- Desde que enquadramento esta perspectiva pode ser considerada?

- Que fatos interferiram na consolidação das definições/representações internacionais na área da educação?

- É possível reconhecer a especificidade e nominar categorias para um enfoque internacional aplicado à educação escolar?

\section{Primeiras espostas}

a) O sentido de perspectiva internacional na área da educação

Neste estudo, o termo "perspectiva" está empregado com o sentido 
de "ver através de". O adjetivo "internacional" abre a observação para toda representação ou ponto de vista que se aplique à prática educacional em escala planetária, global, mundial, regional...A hipótese de trabalho considera que, frente ao que se poderia chamar de "panorama internacional", os Autores adotam abordagens ou enfoques específicos.

O enfoque internacional, portanto, entendido como concepção metodológica da perspectiva internacional, apresenta uma dimensão política, pois o "panorama" é expressivo de uma suposta "ordem internacional". A ordem internacional, por sua vez, constitui uma parte de uma ordem social mundial que integra o conjunto de todas as instituições que globalmente configuram uma sociedade e controlam os meios de realização de seus objetivos.

A área da educação, à qual se aplica a perspectiva internacional, contempla todas as ações intencionais de formação que se inscrevem no âmbito da escola ou de programas que pretendam a sua equivalência.

Portanto, o sentido de perspectiva internacional na área da educação abrange o conjunto de temas e enfoques que tratam da política e das práticas educacionais escolares ou equivalentes convertidos por uma escala de observação que transcende os limites das unidades geopolíticas nacionais.

b) $\mathrm{O}$ ponto de partida da apreensão (ou, o enquadramento preliminar) da perspectiva internacional na área da educação

O estudo da matéria educacional internacional exige uma primeira tarefa, que é a reconstrução da prática de intercâmbio neste campo, pois ela (a matéria internacional) é subproduto de influências, empréstimos e outras transações de bens, pessoas, idéias e serviços pedagógico específicos entre dois ou mais agentes sociais pertencentes a sistemas nacionais diferentes.

O contorno deste movimento, bem como as redes transacionais que se estabelecem, constituem o que passamos a denominar de contexto transnacional de intercâmbio pedagógico .Ao conjunto de efeitos, do intercâmbio pedagógico internacional, estabilizados no tempo e que podem comprometer politicamente a prática educacional dos sistemas educacionais nacionais, denominamos campo institucional internacional da educação.

Assim, a orientação geral do tratamento das práticas e proposições em matéria educacional em escala internacional passa a se reger por pressupostos derivados da conjugação de todos os termos até aqui mencionados.

As representações referentes às transações transnacionais, que constituem a perspectiva internacional, tal como se entende neste trabalho, relacionam-se ao campo institucional internacional, onde se considera que:

- a evolução do intercâmbio pedagógico (transação de bens, pessoas, idéias e serviços) ocorre dentro de um processo social global; 
- o intercâmbio pedagógico internacional se incrementa a partir das exigências de desenvolvimento dos sistemas nacionais de educação;

- as etapas, o conteúdo e as formas de intercâmbio estão relacionadas com uma tipologia específica das relações internacionais aplicável ao campo educacional;

- há um vínculo do intercâmbio pedagógico com a ordem internacional vigente;

- as representações que se dão no campo institucional internacional da educação refletem um estilo internacional, isto é, demonstram um posicionamento crítico ou de conformidade com a ordem internacional vigente;

- a matéria internacional representada é subproduto, em grande parte, das formulações comparativas.

c) Evolução das bases forjadoras da perspectiva internacional na área da educação

O campo institucional internacional da educação, a partir do qual e sobre o qual se elabora a perspectiva internacional, teve sua evolução patrocinada por duas ordens de fatores:

- fatores sociológicos, entre os quais se destacam o expansionismo, o integracionismo, pela tendência organizacional mundial , o desenvolvimento científico e tecnológico, as migrações e as implicações da ordem internacional estabelecida;

- fatores específicos, entre os quais se incluem o desenvolvimento dos sistemas educacionais nacionais, a profissionalização da educação institucional, o desenvolvimento científico e tecnológico educativo e a formulação comparativa da educação.

Interpreta-se o expansionismo como expressão do progresso das relações das unidades sócio-políticas que redunda numa hierarquia planetária. Esta progressão das relações sociais deve ser interpretada sob a égide de uma dialética de poder que gera a assimetria do espaço político.

A configuração do espaço desigual constitui um elemento explicativo das teorias da acumulação mundial e da dependência. A divisão do espaço em tais termos favorece um processo de polarização que reproduz a influência expansionista mediante relações de poder ou dominação.

No intercâmbio pedagógico, identifica-se a dominação cultural, a qual, segundo FURTER (1978) supõe que as relações sociais podem se constituir sobre bases de não-reciprocidade, o que significa dizer que um agente social (país, organismo, instituição...) pode influenciar, manipular, a conduta de outro agente sem que este tenha intenção ou meios de exercer uma ação similar. 
Um expansionismo com tais características, sustenta-se às custas de um processo de integração absorvente, forçada ou persuasiva, que resulta no fenômeno da modernização.

Em todos os tempos se pode encontrar ilustrações das conseqüências do expansionismo na educação escolar. A própria escola é uma invenção européia. Os modelos educacionais transitam de cima para baixo, isto é, dos países desenvolvidos para os menos desenvolvidos. Os sistemas escolares, em seu desenvolvimento, "queimam" etapas e perdem a originalidade residual por ação do expansionismo.

Outro fator sociológico de consolidação do campo institucional internacional educacional é o integracionismo, ou, a motivação associativista que regulou as relações entre as nações. A sociedade internacional, que hoje conhecemos, apresenta-se sob a arbitragem de acordos, mediações, consultas, normas, dentro de uma feição multiforme de associação.

Os agrupamentos internacionais se definem com contornos geográficos ou definidos por afinidades temáticas ou por ambos. Eles supõem a adoção de estruturas orgânicas permanentes, as quais têm por função garantir 0 desenvolvimento e o crescimento de programas solidários ou de ação integrada.

A educação sempre esteve presente, enquanto pauta social, nos programas das organizações internacionais que cuidam do desenvolvimento cultural. Os próprios movimentos integracionistas, como o panamericanismo e 0 Mercosul, para ilustrar a nossa ecologia continental, reservaram ações que se aplicam à área educacional.

Por outro lado, a plasticidade, demonstrada pelas organizações internacionais ao estender sua ação sobre a problemática educacional, induz a consolidação de estruturas paralelas com ascendência sobre as decisões nacionais nesse campo. A UNESCO, o Bureau Internacional de Educação, a OCDE, a Comunidade Européia, a OIT, para citar os organismos governamentais mais conhecidos, desfrutaram das atribuições normativas com ressonância universal. Outras organizações internacionais não governamentais também desempenham atividades de intercâmbio e divulgam representações educacionais que repercutem sobre as políticas nacionais ou sobre inovações educacionais localizadas (Observação: Em 1971, figuravam 28 associações de pessoal docente no rol das organizações internacionais não governamentais, segundo dados constantes nos Repertórios Internacionais de Educação da UNESCO).

A assimetria entre os espaços sociais, derivada do expansionismo, tem servido de justificativa para o desenvolvimento de programas de ajuda, de cooperação e de assistência técnica no campo do desenvolvimento científico e tecnológico, e, em conseqüência, da educação.

No entanto, não se pode abstrair os ânimos e as intenções latentes, freqüentemente contraditórios, do movimento dos centros reitores para a pe- 
riferia. Todo fenômeno de solidariedade que se manifesta no plano internacional entre diferentes interlocutores sociais, confessionais, profissionais ou ideológicos, dizia MERLE (1976), em sua obra sobre a sociologia das relações internacionais, pode desembocar na constituição de um polo de influência.

Assim, ao relacionarmos o desenvolvimento científico e tecnológico com intercâmbios que consolidam o campo institucional internacional educacional, devemos ressaltar o papel de receptadora e de mediadora da educação nesse processo: se, por um lado, ela sofre o influxo do desenvolvimento científico e tecnológico, de outro e ao mesmo tempo, ela servirá de meio terapêutico para o quadro de tensão "cultura-ciência" que inevitavelmente se produz. A interpretação da tensão que ocorre entre a cultura e a ciência reconhece a possibilidade das culturas assimilarem o desenvolvimento científico sem apresentarem perda de sua especificidade desde que a assimilação sofra mediação pedagógica (Entenda-se mediação pedagógica como situação que instrumentaliza a tomada de consciência formal e social em relação à nova informação ou conhecimento).

Na seqüência dos fatores que condicionam a evolução do intercâmbio pedagógico e, em decorrência, contribuem à consolidação do campo institucional internacional educacional, destacam-se as migrações.

A migração constitui, em princípio, um deslocamento geográfico de pessoas, que pode ser compulsório ou voluntário. Esta mobilidade multilateral suscita, no plano escolar, uma contínua reinserção escolar da população em idade formativa convencional, bem como a criação de normas de conciliação da formação. Para isto têm servido os estudos de comparabilidade de certificados e diplomas introduzidos pela UNESCO e agora disseminados nas políticas integracionistas regionais.

Finalmente, o último fator nominado que incide sobre o espaço educacional internacional é a própria ordem internacional. A ordem internacional representa parte da ordem social mundial, pois que engloba o conjunto de todas as relações e instituições formais e informais que unem os cidadãos de diversos países.

A rede de sustentação da ordem internacional está composta por uma estrutura de poder que emana de contatos bilaterais e multilaterais, dentro de um quadro de interdependência mundial causada pela necessidade de alimentos, pela necessidade de energia e de minerais, provocada pela possibilidade de perturbar ou destruir os sistemas que susten tam a vida na nave espacial Terra e gerada pelas esperanças de redução das disparidades evidentes que existem en tre ricos e pobres no mundo (TINBERGEN, 1977). Não são gratuitas as prioridades programáticas dos grandes organismos internacionais, como, por exemplo, as linhas de pesquisa e financiamento para a educação ambiental patrocinadas pela ONU e pelo Banco Mundial. 
Assim, tem sido mais ou menos fácil constatar que toda pauta regenerativa de uma ordem internacional resgata a força do papel da educação na superação das disparidades sociais e econômicas existentes no mundo. Com isso, fornece-se mais munição ao campo institucional de que trata 0 presente texto.

Como se situa e em que direção mais específica interage o intercâmbio pedagógico internacional de modo a adensar o campo institucional nesta mesma escala?

A expansão e o adensamento do campo institucional internacional da educação têm estreita relação com o desenvolvimento dos sistemas nacionais e a profissionalização da educação institucional ou escolar convencional. Ou seja, poder-se-ia afirmar que a perspectiva internacional existe porque a antecede uma circunstância técnica de natureza pedagógica e com caráter político administrativo que sugere uma proposição social estratégica.

Aliás, é este movimento de ordenação nacional dos sistemas escolares que projeta o intercâmbio pedagógico, em seus primórdios, enquanto recurso de empréstimo. $\mathrm{O}$ estudo sobre as reformas educacionais e outras inovações, nos nossos dias, revela uma prática generalizada de transplantes de soluções educacionais que ainda não foi controlada e/ou criticada suficientemente (CERVI, 1984, 1985).

A globalização a que está submetido o nosso planeta neste fim de século exacerba a adoção de padrões operacionais uniformes que constrangem, por sua vez, as liberdades nacionais de estabelecerem um projeto educacional peculiar. A desterritorialização das sociedades interpõe exigências altamente niveladas para as formações dos contingentes populacionais que pleiteiem disputar não mais o emprego e sim a empregabilidade em um cenário econômico regido pela competitividade.

Mais além do movimento de ordenação nacional, a formulação comparativa intensificou o intercâmbio pedagógico, conferindo-lhe uma autonomia relativa em alguns casos. Ou seja, estamos convencidos de que a perspectiva internacional existe porque lhe antecede um fluxo multilateral de pessoas e idéias que fazem factível uma formulação de interesse comum.

Os estudos comparados mostraram que os problemas educacionais não são exclusivos de cada país e que se justifica plenamente buscar e compreender forças e fatores fora das fronteiras das sociedades para incrementar os critérios das decisões políticas em cada realidade. Ora, este mesmo movimento vai insinuar os estudos sobre as origens e as influências sobre os sistemas escolares (NOAH, 1984, 1989).

A perspectiva internacional aloca, pois, estes tipos de abordagens sobre a dispersão dos modelos educacionais ou o seu inverso, as "endemias" educacionais. A matéria gerada pelas intensas transações movidas pelo inte- 
resse político recíproco sobre os projetos educativos nacionais e institucionais constituiu, não só o conteúdo embrionário da epistemologia comparativa como o conteúdo genético da perspectiva internacional da educação.

$\mathrm{O}$ intercâmbio pedagógico internacional fez evoluir as bases teóricas de troca. Assim, o que antes não passava de um limitado repertório sobre a educação estrangeira, qualificado por NOAH e EKSTEIN (1970) de "enfoque pantométrico", converteu-se, pela evolução a um intercâmbio pedagógico menos assimétrico voltado a estratégias bilaterais ou multilaterais, ao que estamos insistindo em denominar de perspectiva internacional.

Apresentadas todas estas "primeiras questões", queremos ressaltar, em síntese, o componente formal principal da perspectiva internacional na área da educação, que é: o estilo internacional.

Mais concretamente, o estilo internacional pode ser considerado a partir das alternativas possíveis de compreensão, valorização e aplicações políticas geradas essencialmente por um fenômeno-base expansionista (mundialização e globalização são expressões distintas que aí se incluem) que promove e justifica, por sua vez, as formas contemporâneas de intercâmbio transnacional e sua correspondência com o que poderíamos chamar de pauta político-educativa mundial potencial.

\section{Comentá rio final}

A possibilidade de reconhecer a especificidade de um domínio - 0 da perspectiva internacional na área da educação - se nos parece, cada vez mais, concreta, pertinente e imprescindível. No entanto, o tratamento teórico impõe a exploração de categorias para uma apropriação conceitual abrangente e crítica.

Este comentário não significa, entretanto, que, a finais da década de 90 não tenham se consolidado os estudos nesta perspectiva. O que pretendemos, com toda a ilusão, é que, com o convencimento da especificidade e propriedade de tal enfoque, sobrem razões para inserir a perspectiva internacional no contexto das trajetórias formativas dos gestores sociais e dos educadores, par começar.

O destaque dado à perspectiva internacional na área da educação deve interessar especialmente aos comparatistas educacionais brasileiros. Contudo, precisamos reconhecer que o nosso educador, de um modo geral, não se distancia do seu cenário, seja em corpo ou espírito, e os esforços dos especialistas (comparativos) podem permanecer elitistas, ilhados e desconsiderados, ou todas estas coisas. 
Mas, é absolutamente imperioso que se insista na regeneração dos estudos comparados em educação, que, desde a década de 60, encontram-se desestimulados.

Nos dias de hoje, as questões da globalização e da integração regional, reforçam a necessidade de se reanalisar os espaços formativos, os novos espaços sobre os quais se projetam as políticas educacionais, individuais e em conjuntos, os princípios que fazem as intervenções político-educacionais transcenderem as configurações geográfico-históricas.

A Europa, em avançado estado de articulação, cede, neste momento, sua experiência integracionista. Pensadamente resistentes, nossas escolhas acadêmicas sobreviveram. Ainda entendemos que é hora de recapitular a experiência passada e de buscar o sentido do que se faz contemporâneo . É hora, também, de avançar. Temos pretextos recentes, no âmbito regional, para a construção de um processo internacional estreito, de feição solidária.

Retomar a conversa, para realinhar as abordagens no nosso cotidiano, num sentido de reinventá-las, redescobrí-las, porque il 'est plus important d'avoir des idées que de connaître des verités (VEYNE, 1976). Diante desta probabilidade, que o grande geógrafo MILTON SANTOS nos ceda, com maior significado neste caso, a auto-crítica com que fechou a introdução da $4^{\text {a }}$. edição de seu livro "Por uma geografia Nova" $(1996$, p.9) :

Assim, o melhor é fazer como Woodbridge (1940,p.11) quando, a propósito do seu livro 'An Essay on Nature', escreveu que 'naquilo que escrevi fui profundamente sério, mas muitas vezes tive que sorrir das minhas afirmações cada vez que buscava professar com autoridade.

\section{Referências bibliográficas}

CERVI, R. de M. La perspectiva internacional en el area de la educación.

Tesis de Doctorado. Barcelona: Universidad de Barcelona, 1981.

. La perspectiva internacional en el area de la educación. Barcelona: Universidad de Barcelona, Centro de Publicacions, Intercanvi Cientific i Extensió Universitaria, 1981, $34 \mathrm{p}$.

Transferência em educação. In: Em Aberto. Brasília: MEC-INEP, 1984, Ānō 3, (24): 19-23.

. Pluralismo linguístico e educação. Correio de Notícias. Curitiba, 1.ㅇ 11/1985.

- Evolução da conotação política dos estudos comparados em educa-

ção. In: Revista Educar. Curitiba: UFPR, 1985, Vol 4 (1), p.73-92. 
. O significado curricular da Educação Comparada. In: Revista Educar. Curitiba: UFPR, 1986, Vol 5 (1/2), p.33-60.

- A Educação Comparada no Brasil. (Folheto) Curitiba, 1987.

- Marcos teóricos da comparação em educação. In: Caderno Aberto. Cūitiba: Programa de Pós-Graduação em Educação da UFPR, 1989, Vol 2 (1), p.13-20.

. Política e gestão da integração da educação no âmbito do Mercosul: a reflexão necessária. In: Administração da Edu cação Superior-Apontamentos. Curitiba: PUCPR/Pós-Graduação em Educação-Mestrado. Maio de 1999, Ano l (2), p.13-24.

FURTER, P. Introduction à une méthode contextuelle d'analyse comparée. Genève: FAPSE, Université de Genève, 1978.

. Les relations internationales dans le développement de l' éducation: perspectives et perplexités. In: Education Comparée. Sèvres, (20-21), septembre-décembre, 1979, p.7-20.

LE THANH KHOI. L'éducation comparée. Paris; Armand Collin, 1981.

MARQUEZ, A.D. Educación Comparada. Teoría y metodología. Buenos Aires: El Ateneo, 1972.

. L'Education Comparée etl'Education Internationale. Leur place dans la systématique pédagogique et leur rapport avec la réalite. $\mathrm{X}$ ème Conférence de la CESE, Genève, 1981.

MERLE, M. Sociología de las relaciones internacionales. Madrid: Alianza Editorial, 1978.

NOAH, H.J. Usos y abusos de la educación comparada. In: Nuevos enfoques en educación comparada. Madrid: Mondadori, 1990.

NOAH, H.J. e EKSTEIN, M.A. La ciencia dela educación comparada. Buenos Aires; Paidós, 1970.

SANTOS, M. Por uma geografia nova. São Paulo: HUCITEC, 1996.

TINBERGEN, J. (coord.) Reestruturação da ordem internacional. México: Fondo de Cultura, 1977.

VEYNE, P. L'inventaire des différences. Paris: Seuil, 1976. 
Ementa: Este Artigo define e enquadra a perspectiva internacional na área da educação, enquanto domínio de conhecimento acadêmico. Vincula o intercâmbio pedagógico a uma ordem internacional; relaciona as representações que se dão no campo institucional internacional a um estilo internacional; situa as formulações comparativas como referencial antecedente da perspectiva internacional na área da educação; situa e descreve as bases forjadoras desta perspectiva.

Palavras-chave: educação internacional, educação comparada, campo institucional internacional da educação, intercâmbio pedagógico internacional, contexto educacional transnacional 